Supplemental figure S2: Mapping of DArT-Seq ${ }^{\mathrm{TM}}$ and non-DArT-Seq markers in relation to their recombination fractions and physical map positions on $A$ and $C$ genomes of $B$. rapa and $B$. oleracea, respectively.

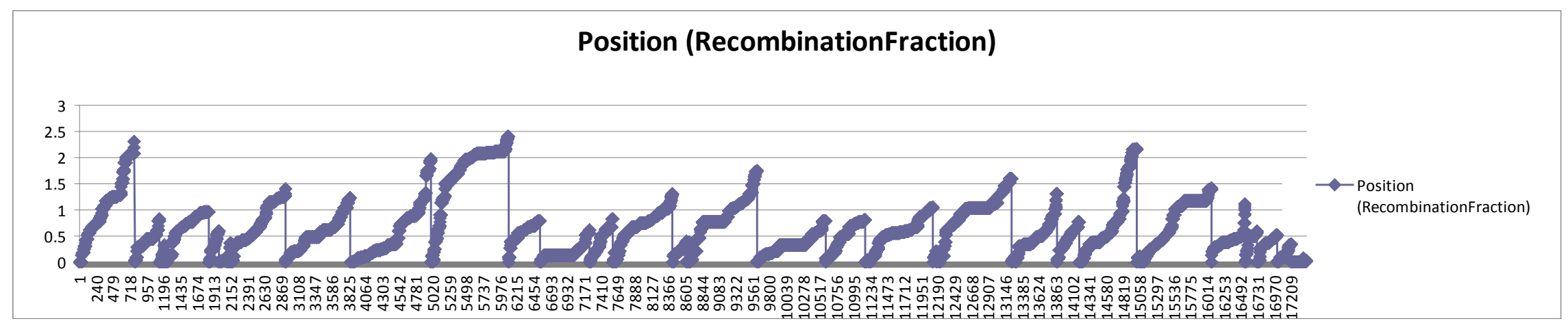

\title{
Position (Physical)
}

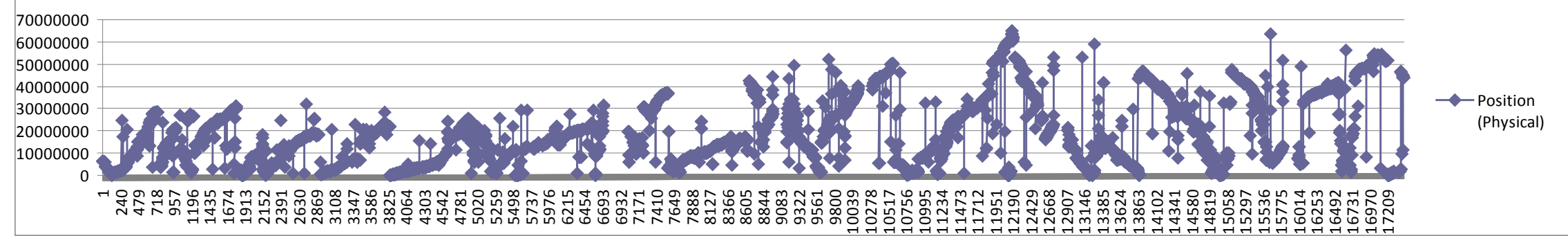

